\title{
Penetrating Ocular Trauma Caused by Steel Wire from a Rotating Wire Brush: A Case Report with Review of Literature
}

\author{
Sagili Chandrasekhara Reddy
}

\section{ABSTRACT}

\begin{abstract}
A 19-year-old young man came to emergency department with a complaint of injury in the left eye with a wire, while cleaning the car engine parts in the workshop with motorized rotating wire brush. He was referred immediately to the eye clinic. On examination of the left eye, a thin steel wire was seen penetrating at the nasal limbus which was projecting forwards. The wire was removed (33 $\mathrm{mm}$ in length) under aseptic precautions using topical anaesthesia. Postoperatively, he was treated with ciprofloxacin eye drops. The patient had no ocular morbidity; the vision was normal, and he was asymptomatic in the left eye. Eye injuries from rotating wire brushes are caused by detached fragments. These eyes should be examined in detail for the involvement of different structures of the eye; and should be treated adequately in-time to prevent visual loss/ blindness. Wearing of safety glasses/ full face shield while working is recommended to prevent such injuries.
\end{abstract}

Keywords: Ocular trauma, penetrating injury, limbus, steel wire, rotating wire brush.

\section{INTRODUCTION}

Penetrating /perforating eye injuries caused by rotating wire brushes are sight threatening that can be prevented. Rotating brushes are used to remove rust from the parts of different items in the mechanical workshops and to clean rusty metal sheets before painting. The literature search (PubMed, Science Direct, and Google Scholar) revealed only ten reports as individual cases or case series (seven in English language [1]-[7] and three in other than English language (German [8], Hebrew [9], and Czech [10]) from different parts of the world, and none from Asian countries. Therefore, this rare case of penetrating injury of left eye caused by a steel wire from a rotating wire brush in a young car mechanic is reported, with review of literature. To the best of author's knowledge, this is the first case repot from Asia.

\section{CASE REPORT}

A 19-year-old young man came to emergency department of the teaching government general hospital at $10.30 \mathrm{am}$ with a complaint of injury with a wire in the left eye, while cleaning the car engine parts in the workshop with motorized rotating wire brush. He was not wearing any protective glasses while doing the work. He was brought by his friend immediately to the hospital. He had slight blurring of vision and mild pain in the left eye. He was given injection tetanus toxoid in the emergency department; and immediately
Submitted : April 05, 2021

Published : April 26, 2021

ISSN: $2593-8339$

DOI: $10.24018 /$ ejmed.2021.3.2.804

Sagili Chandrasekhara Reddy * Department of Ophthalmology, Rangaraya Medical College, Kakinada, Andhra Pradesh, India.

Department of Ophthalmology, Faculty of Medicine and Defence Health, National Defence University of Malaysia, Kuala Lumpur, Malaysia. (e-mail: profscreddy@gmail.com)

*Corresponding Author referred to the eye clinic.

Examination of left eye: Vision was 6/9. There was mild circumciliary congestion. Cornea was clear. A thin wire with multiple small curves was seen penetrating the nasal limbus at $8.30 \mathrm{o}$ 'clock position. In primary position (Fig. 1) and the downward position of the eye (Fig. 2), the wire was seen projecting forwards. Slit lamp examination did not show any abnormality in the rest of the anterior segment. Good red reflex was seen in the pupil with slit lamp in retro illumination method of examination.

Examination of the right eye: The vision, anterior segment and fundus were normal.

The patient was explained about the nature of the injury and advised removal of the wire under topical anaesthesia. Informed consent was taken. The wire was removed in the minor operation theatre under aseptic precautions. The patient in supine position, xylocaine eye drops $4 \%$ were put at one minute interval for three times. The eye was washed with normal saline. The wire was grasped with a straight artery forceps at its tip and pulled upwards. Gentle pressure was applied on the wound with a cotton bud on which ciprofloxacin eye drops $0.3 \%$ were put. There was no leak of aqueous from the wound and anterior chamber depth was normal. Ciprofloxacin eye drops $0.3 \%$ and same eye ointment were put, and the left eye was patched. The removed steel wire was $33 \mathrm{~mm}$ in length (Fig. 3). 


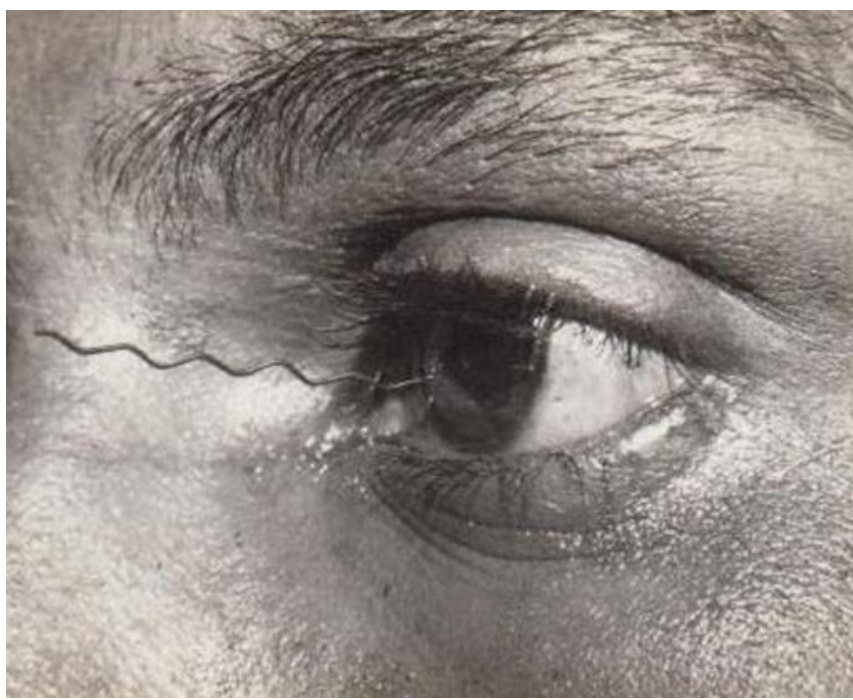

Fig. 1. Left eye in primary position showing a thin wire with multiple small curves penetrating the nasal limbus at $8.30 \mathrm{o}$ 'clock position; the wire is seen projecting forwards

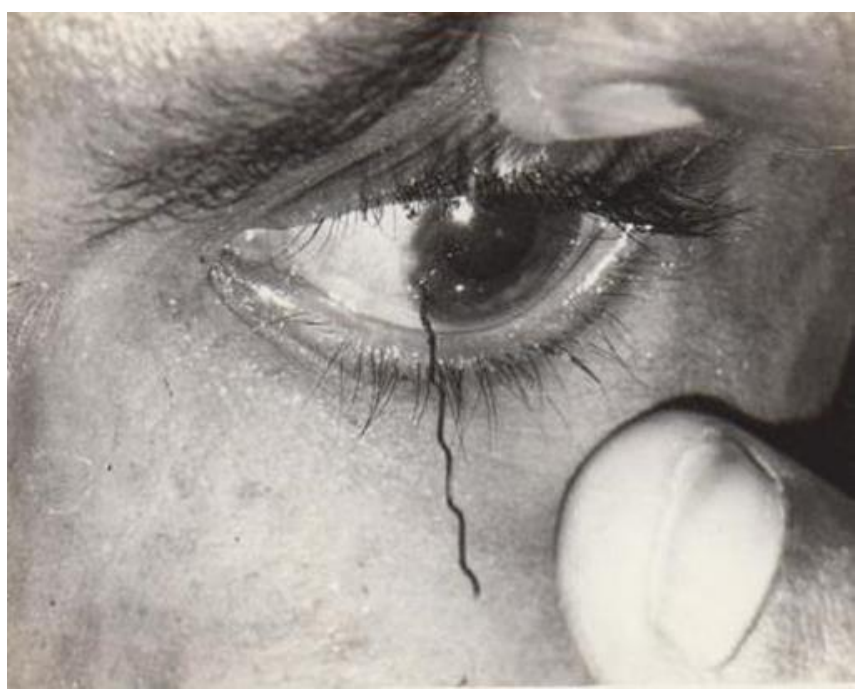

Fig. 2. Left eye looking downwards showing the wire penetrating the nasal limbus, which is seen projecting forwards.

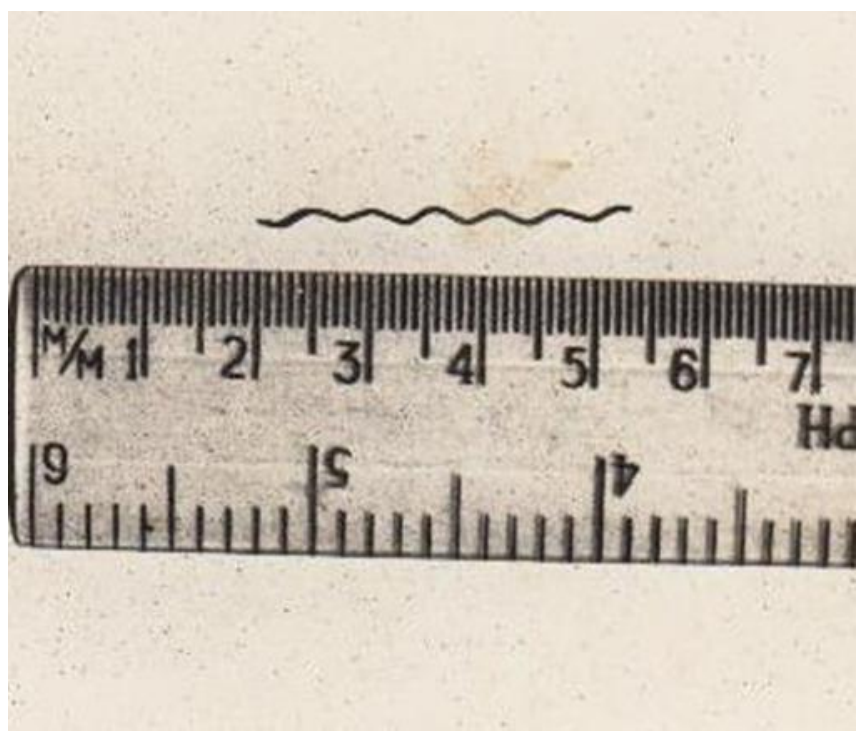

Fig. 3. The removed thin steel wire with multiple curves (33 mm long).
The patient was admitted in the eye ward for further investigations. On the first postoperative day, vision in the left eye was 6/6; conjunctiva was normal. There was no pain in the eye. Ciprofloxacin eye drops $0.3 \%$ were put four times daily and the same eye ointment in the night time. On the next day, X-ray orbits did not show any opaque foreign body in the left orbit indicating no intraocular foreign body. On third postoperative day, the wound on the nasal limbus healed completely. Applanation intraocular pressure was $18 \mathrm{~mm} \mathrm{Hg}$ in both eyes. The gonioscopy did not show any micro hyphema and the angle was open in all the quadrants in the left eye. Dilated pupil slit lamp fundus examination with 90 D lens showed that optic disc, macula and retina were normal in the left eye.

The patient was discharged on ciprofloxacin eye drops $0.3 \%$ four times daily for one week and then three times daily in the left eye; and advised to come for follow up after two weeks. The patient's left eye was white and quiet with normal vision during the biweekly follow up for one month. He was advised to come to eye clinic for immediate checkup if he feels any problem in the left eye.

\section{DISCUSSION}

Any structure in the eye can be involved in patients with ocular trauma. It is essential for all the ophthalmologists to use standard terms for eye injuries which conveys single interpretation without any ambiguity. This helps in decision making and management of these cases. In Birmingham Eye Trauma Terminology (BETT), all the terms relate to the whole eyeball as the tissues of reference and the injuries were classified as closed globe and open globe injures (Fig. 4). These terminologies are used in everyday practice by all ophthalmologists all over the world. Penetrating and perforating injuries of cornea and/or sclera come under open globe injuries [11]. Penetrating injury by definition is the one caused by usually sharp object which penetrates into the eye but not through and through; and there is no exit wound; while perforating injury of the eye has both entrance and exit wounds. Usually, a full thickness rupture of the cornea and/or sclera is present in perforating injury.

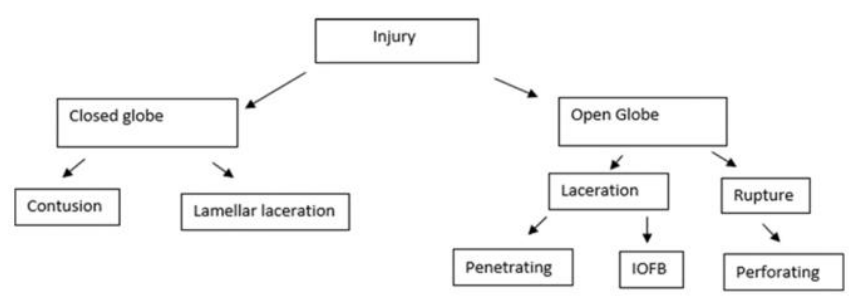

Fig. 4. Birmingham Eye Trauma Terminology. IOFB = intraocular foreign body.

Rotating wire brushes are composed of fine wire brushes projecting from one side of a metal wheel usually attached to an electric drill. While doing the work with this, individual bristles which break off are sharp objects and may penetrate or perforate cornea/sclera if they hit the eye. When wheel brush is used at high revolutions the detached fragments come out with increasing speed causing perforating injury, and sometimes a retained intraocular foreign body [12]. 
Purtskhvanidze et al [6] reported 20 cases (all male patients, aged between 19 and 80 years) of traumatic ocular injuries by rotating wire brushes over a period of 15 years. Eleven of them happened at work and nine at home. Eighteen injuries were penetrating, one was perforating; and in one case intraocular foreign body was present. Protective/safety glasses were not used by any of the patients at the time of injury. The mean length of foreign bodies was $14.1 \mathrm{~mm}$ (range 3-23 mm) and mean diameter was $260 \mu \mathrm{m}$ (range 100$400 \mu \mathrm{m}$ ). The mean time frame from injury to admission was three hours. Anterior segment of the eye was involved in all the 20 eyes (cornea in 17, sclera in 3, iris in 6, lens in 10); and posterior segment of the eye in 10 eyes (vitreous body in 10 , retina in 3 , choroid in 1 ). In their study, the mean best corrected visual acuity at admission was 2/20 (range light perception - 20/20) and at the last follow up (6 to 67 months) it was $10 / 20$ (range $2 / 20-20 / 20$ ).

Constans and Rao [5] reported a 51-year old man who sustained a penetrating injury to the left eye during home improvement work with a motorized wire brush to resurface a piece of sheet metal. During the wok, a $16 \mathrm{~mm}$ wire broke free from the brush and penetrated his left eye. Patient's son immediately removed the intact wire with a pair of tweezers and visited a local urgent care centre. He was given tobramycin eye ointment and advised to see the ophthalmologist next morning. This patient had a full thickness corneal laceration, traumatic cataract with disruption of anterior capsule and underlying cortex.

In three patients reported by Hassett and Cleary [1], one patient had corneal perforation, traumatic cataract, and damage to iris sphincter; another patient had full thickness corneal wound; and third patient had corneal perforation, iris wound, traumatic cataract with posterior capsule tear.

Hod and Geyer [9] reported three cases and in all of them the wire brush penetrated the cornea, iris, and lens; in one case endophthalmitis developed.

Efthymios et al [7] described a case of penetrating eye injury to the right eye caused by rotating wire brush in a 42 year-old fighter pilot who had a retained intraocular foreign body of $22 \mathrm{~mm}$ size, with only $1 \mathrm{~mm}$ protruding out from the cornea. The wire was surgically removed. Postoperatively, he developed traumatic cataract, vitreous haemorrhage for which parsplana vitrectomy and phacoemulsification with intraocular implantation were done. A retinal tear without retinal detachment was found where the wire was attached to the retina, and it was sealed with endolaser photocoagulation. The corrected visual outcome was 20/20, making him fit to return to active duty.

Chan and Hawksworth [2] described a case of corneoscleral perforation by a piece of wire from a rotating brush in a 37-year-old man, who immediately removed it (3 $\mathrm{cm}$ long fragment) before coming to hospital. There was no intraocular foreign body. However, he developed endophthalmitis postoperatively after primary repair of the wound.

Paul and Lewis [3] described a case of superficial penetrating eye injury secondary to use of rotating wire brush, despite the use of safety glasses. They suggested that wearing safety glasses is not adequate and recommended the use of full-face shield during all professional and domestic works involving rotating tools.
The final visual outcome in these eyes depends on the length and thickness of the detached fragment, the mechanism of injury, the affected tissues in the eye, the time between the injury and seeking treatment, and the presence of complications in the eye. Early surgical intervention usually results in good visual outcome unless there is preexisting endophthalmitis in the injured eye. In addition to medical treatment with broad spectrum antibiotic eye drops, surgery may be needed depending on the severity of trauma. In case of perforating injury of cornea/sclera, wound repair is required. If there is traumatic cataract, phacoemulsification with intraocular implantation is needed to improve vision. If there is endophthalmtis, parsplana vitrectomy is required.

In the present case, the patient did not interfere with the wire after the injury in the left eye and came to the hospital within short time. He had only a penetrating injury at the limbus with good vision and other tissues in the eye were not involved. The wire was removed from the limbus within one hour from the time of injury. Most probably all these facts have contributed to an excellent outcome without any ocular morbidity in the left eye of this patient.

\section{CONCLUSION}

Ocular trauma caused by rotating wire brush fragments can result in penetrating/perforating injury to cornea/sclera, retained inraocualr foreign body, traumatic cataract, injury to iris, and endophthalmitis. Therefore, detailed examination of the eye and radiological evaluation for intraocular foreign body are essential in these cases. Appropriate medical and surgical treatment should be given in-time to save the vision in these eyes. Specific prevention strategies to avoid the mechanism of injury with the help of posters in the mechanic workshops and hardware stores would be useful to educate the people. The use of wide safety glasses should be made mandatory for all people working in the mechanic workshops to prevent such injuries because the eye blink reflex, within the short time before the impact of the detached wire fragment occurs, is not possible.

\section{REFERENCES}

[1] Hassett P, Cleary PE. Serious eye injuries caused by rotating wire brushes. Br J Ophthalmol 1994;71:491.

[2] Chan HY, Hawksworth NR. Serious eye injuries caused by rotating wire brushes. Br J Ophthalmol 1995;79:396.

[3] Paul A, Lewis A. Safety goggles: are they adequate to prevent eye injuries caused by rotating wire brushes? Emerg Med J 2008;25:385.

[4] Phillips D. Penetrating ocular trauma, Eyerouds.org dated 31 March 2014, University of Iowa health care, Ophthalmology and Visual sciences. https://eyerounds.org/atlas/pages/ Penetrating-oculartrauma/index.htm (accessed on 10 March 2021).

[5] Constans J, Rao NK Man presents 18 hours after penetrating injury to left eye. Ocular surgery news. October 20, 2016. https://www.healio.com/news/ophthalmology/20161014/manpresents- 18-hours-after-penetrating-injury-to-left-eye (accessed on 10 March 2021).

[6] Purtskhvanidze K, Rüfer F, Klettner A, Roider J. Ocular Trauma Score as prognostic value in traumatic ocular injuries due to rotating wire brushes. Graefes Arch Clin Exp Ophthalmol 2017; 255:1037- 42.

[7] Efthymios KI, Evangelos ME, Thomas NG, Konstantinos KM, Ioannis GP. Rotating wire brush ocular trauma in a fighter pilot. Indian J Ophthalmol 2020; 68: 2279-81.

[8] Höh H, Krannig HJ. Perforating injuries of the eyes caused by rotating steel brushes. Klin Monbl Augenheilkd 1990; 196: 166-70. (Article in German). 
[9] Hod Y, Geyer O. Eye injuries caused by rotating wire brushes. Harefuah. 2005; 144: 239-40, 304 (Article in Hebrew).

[10] Hlavácová $\mathrm{P}$, Dosková $\mathrm{H}$. If you say "better than with the wire into the eye" - a case report. Cesk Slov Oftalmol. 2007; 63: 63-6 (Article in Czech).

[11] Kuhn F, Morris R, Witherspoon CD. Birmingham eye terminology system (BETT): terminology and classification of mechanical injuries. Ophthalmol Clin North Am 2002; 15: 139-43.

[12] Safety in the use of abrasive wheels. Health and safety series booklet HS(G)17. London: Health and safety executive, 1991. 